\title{
GOVERNANCA EDUCACIONAL GLOBAL E A GÊNESE DOS TESTES DAS HABILIDADES SOCIOEMOCIONAIS
}

\section{CARLOS EDUARDO SERRINA DE LIMA RODRIGUES CLAUDIA DE OLIVEIRA FERNANDES}

* Este artigo é uma versão revisada do trabalho publicado nos anais da 37ª Reunião da Associação Nacional de Pós-Graduação e Pesquisa em Educação (ANPEd), que ocorreu nos dias 4 a 8 de outubro de 2015 , na Universidade Federal de Santa Catarina, em Florianópolis.

\section{RESUMO}

O discurso de que as economias estão cada vez mais inter-relacionadas tem justificado o papel de destaque que a Organização para a Cooperação e Desenvolvimento Econômico (OCDE) tem desempenhado em relação à educação e, especialmente no que tange à investigação que originou este texto, o enaltecimento que a Organização tem dado às habilidades socioemocionais. Propomo-nos a investigar em que medida seria possível identificar na atuação da OCDE mecanismos que comprovem a existência de um projeto de governança educacional global. A aplicação do instrumental analítico proposto por Charaudeau (2014) aos documentos que compuseram nosso corpus permitiu-nos afirmar que a OCDE tem posto em prática um verdadeiro projeto de governança educacional global, constituindo os três mecanismos de governança apontados por Jakobi e Martens (2010): a produção de ideias, a avaliação de políticas e a geração de dados; assim como os modos de governança cognitivo e normativo, concebidos por Woodward (2009).

PALAVRAS-CHAVE POLÍTICAS EDUCACIONAIS - AVALIAÇÃO DA EDUCAÇÃO • HABILIDADES SOCIOEMOCIONAIS • GOVERNANÇA EDUCACIONAL GLOBAL. 


\section{GOBERNANZA EDUCACIONAL GLOBAL Y LA GÉNESIS DE LOS TESTS DE LAS HABILIDADES SOCIOEMOCIONALES \\ RESUMEN}

El discurso de que las economías están cada vez más interrelacionadas ha justificado el papel de destaque que la Organización para la Cooperación y Desarrollo Económico (OCDE) viene jugando en relación a la educación y especialmente en lo que atañe a la investigación que originó este texto, el enaltecimiento que la Organización ha dado a las habilidades socioemocionales. Nos proponemos a investigar en qué medida sería posible identificar en la actuación de la OCDE mecanismos que comprueben la existencia de un proyecto de gobernanza educacional global. La aplicación del instrumental analítico propuesto por Charaudeau (2014) a los documentos que compusieron nuestro corpus nos permitió afirmar que la OCDE ha puesto en práctica un verdadero proyecto de gobernanza educacional global, constituyendo los tres mecanismos de gobernanza señalados por Jakobi y Martens (2010): la producción de ideas, la evaluación de políticas y la generación de datos, así como los modos de gobernanza cognitivo y normativo, concebidos por Woodward (2009).

PALABRAS CLAVE POLÍTICAS EDUCACIONALES • EVALUACIÓN DE LA EDUCACIÓN • HABILIDADES SOCIOEMOCIONALES • GOBERNANZA EDUCACIONAL GLOBAL.

\section{GLOBAL EDUCATIONAL GOVERNANCE AND THE GENESIS OF THE SOCIO-EMOTIONAL SKILLS TESTS}

ABSTRACT

The discourse that the economies are ever more interrelated has justified the major role played by the Organization for Economic Co-operation and Development (OECD) in relation to education and, especially regarding the investigation that led to this text, i.e., the importance the Organization has given to socio-emotional skills. We propose to investigate to what extent it would be possible to identify mechanisms that confirm the existence of a global educational governance project in OECD activities. The application of the analytical framework to the documents that composed our corpus, which was proposed by Charaudeau (2014), allowed us to affirm that the OECD has put into practice a real educational global governance project. This project not only deploys the three mechanisms of educational governance proposed by Jakobi and Martens (2010); the production of ideas, policy assessment and data generation, but also the cognitive and normative modes of governance, designed by Woodward (2009).

KEYWORDS EDUCATIONAL POLICIES • EDUCATION ASSESSMENT • SOCIO-EMOTIONAL SKILLS • EDUCATIONAL GLOBAL GOVERNANCE. 


\section{INTRODUÇÃO}

Articulada às políticas econômicas e ideológicas do neoliberalismo, tem-se observado uma profunda transformação marcada tanto por mudanças nas formas de emprego, nas estruturas organizacionais, nas culturas, nos valores e nas relações sociais, quanto pelos discursos de excelência, efetividade e qualidade aplicados ao setor público (BALL, 2011).

No campo da educação, esse processo tem sido orientado pela inserção da lógica e da cultura do mercado, acompanhadas, conforme apontam Gerwitz e Ball (2011), por um discurso do "novo gerencialismo", em oposição ao discurso do "bem-estar social". Esses dois tipos de discursos ideais apresentam-se contemplados por Dias Sobrinho (2004) em termos de dois paradigmas educacionais: o da educação segundo a lógica do mercado e o da educação como um bem público.

O processo de inserção no campo educacional de concepções e práticas marcadamente associadas à lógica do mercado não estaria, contudo, imune a críticas. Ao contrário, Grubb e Lazerson (2006) denunciam que a imposição de 
uma agenda educacional utilitarista mutila a função cívica da educação e de seus pressupostos democráticos. De maneira semelhante, Ravitch (2011) nos alerta que os processos inerentes ao mercado não são compatíveis com a função democrática da escola pública, na medida em que o mercado é operado segundo a lógica dos ganhadores e perdedores.

O referido cenário é caracterizado também pela ideia de que as economias estão cada vez mais inter-relacionadas, o que faria com que os mecanismos de gestão, baseados nos interesses dos mercados, passassem a escapar aos próprios Estados, sendo assumidos por organizações internacionais, prontas para estabelecer suas diretrizes e compartilhar métodos de gerenciamento.

Nesse contexto, Meyer e Benavot (2013) destacam que a soberania das nações e de seus sistemas de educação tem se enfraquecido em razão da atuação de organizações internacionais, tais como a Organização para a Cooperação e Desenvolvimento Econômico (OCDE). De acordo com os autores, esse processo põe em dúvida o projeto de uma educação pública que teria por propósito o desenvolvimento da cidadania e o fomento à solidariedade como valores, em nome de se atender às demandas econômicas e do mercado de trabalho.

No intuito de avaliar a qualidade da educação, os sistemas educacionais têm, até o momento, aferido apenas as competências e habilidades cognitivas, mais especificamente os conteúdos curriculares das disciplinas de matemática, leitura ou língua nacional (a depender da idade dos estudantes) e, em franca expansão, das ciências.

Tem-se reconhecido, contudo, que aspectos essenciais à formação das nossas crianças e jovens vêm sendo negligenciados nessas avaliações. Muitos especialistas nas áreas da educação, da psicologia e da economia têm defendido que o desenvolvimento das competências e habilidades socioemocionais/não cognitivas - isto é, comportamentos, atitudes e características de personalidade que não estariam diretamente ligadas ao domínio das disciplinas escolares - seria tão ou mais importante para promover o sucesso individual dos estudantes do que as próprias competências e habilidades cognitivas (FARKAS, 2003; HECKMAN et al., 2006; LEVIN, 2012). 
1 A OCDE estabeleceu uma parceria com O IAS para construir um instrumento capaz de aferir habilidades socioemocionais que fosse, ao mesmo tempo. economicamente viável de ser aplicado em larga escala e suficientemente robusto do ponto de vista científico para embasar futuras pesquisas acadêmicas. A validação desse instrumento deu-se por meio da aplicação, em outubro de 2013, de uma avaliação-piloto ma amostra de estudantes da red pública estadual do Rio de Janeiro. Pretendeu-se aferir conscienciosidade amabilidade, estabilidade emocional, abertura a novas experiências extroversão.

Nesse contexto, características como perseverança, autocontrole, motivação e capacidade de trabalhar em grupo (colaboração) têm sido tratadas como habilidades que devem necessariamente se expandir, para que crianças e jovens se desenvolvam plenamente.

No entanto, o atual discurso em favor do fomento às competências socioemocionais tem como alguns de seus interlocutores os organismos multilaterais, os quais parecem conceber a educação na perspectiva da lógica do mercado, ainda que, por vezes, recorram ao discurso do bem-estar social.

No que diz respeito ao fomento das habilidades socioemocionais, o organismo multilateral que mais tem influenciado as discussões no Brasil é a OCDE, a qual vem se articulando com instituições brasileiras, tais como o Instituto Ayrton Senna (IAS), o Ministério da Educação (MEC) e a Coordenação de Aperfeiçoamento de Pessoal de Nível Superior (Capes), no sentido tanto de legitimar o discurso acerca da relevância das habilidades socioemocionais, como de instituir um novo instrumento de avaliação em larga escala que seria capaz de aferi-las. ${ }^{1}$

Diante desse contexto, pretendemos investigar em que medida é possível identificar, na atuação da OCDE em relação à temática das habilidades socioemocionais, mecanismos e posturas que nos permitam compreender se há um projeto de governança educacional global, conforme denunciam Woodward (2009) e Jakobi e Martens (2010).

Este artigo apresenta parte de uma pesquisa maior que teve por objetivo compreender os discursos em torno do enaltecimento dos testes de larga escala para medir as habilidades educacionais, como sendo a nova demanda para uma educação de qualidade. Foi questionado o conceito de qualidade, bem como a validade e legitimidade de tais testes para avaliar habilidades não quantificáveis.

$\mathrm{O}$ recorte deste texto privilegiou a gênese do discurso que põe em relevo as habilidades socioemocionais para a educação, a fim de contribuir para a compreensão da gênese de tais testes que vem tendendo a expandir-se na educação brasileira, nos diferentes níveis de escolaridade, como o 
ASQ 3 para a educação infantil e o projeto-piloto de testes de habilidades socioemocionais no ensino médio, ambos no Rio de Janeiro.

Considerando, por um lado, a perspectiva de Dias Sobrinho (2004, p. 705) de que não há consensos quando o assunto é avaliação - por ser esse um fenômeno complexo que envolveria "questões epistemológicas, éticas, ideológicas, políticas, culturais, técnicas e de outras naturezas" -, e, por outro, a forma com que Ball e Mainardes (2011) dão destaque às crenças e valores discordantes presentes nas políticas, recorremos à Análise do Discurso de linha francesa e, mais especificamente, à proposta de Charaudeau (2014), o qual enfatiza o caráter intersubjetivo da linguagem, já que esta implica a relação ao/com o outro, reconhecendo-a como o espaço do debate e do embate.

Para cumprirmos o objetivo de pesquisa supracitado, aplicamos o instrumental analítico proposto por Charaudeau (2014) aos seguintes documentos, constitutivos de nosso corpus: relatório "Education at a Glance 2013", produzido anualmente pela OCDE (2013a); "PISA 2015: draft collaborative problem solving framework", documento em que a OCDE (2013b) apresenta os fundamentos para a avaliação da habilidade de solucionar problemas de modo colaborativo, que será aplicada com o PISA (Programme for International Student Assessment) de 2015; e dois documentos relacionados ao evento Fórum Internacional de Políticas Públicas "Educar para as Competências do Século 21", realizado, em parceria, pela OCDE, pelo MEC do Brasil e pelo IAS, nos dias 24 e 25 de março de 2014, na cidade de São Paulo, quais sejam: o relatório "Competências para o Progresso Social" e o Sumário realizado a partir do Fórum de Ministros, ambos veiculados no site do IAS. ${ }^{2}$

$2<$ http://www.educacaosec21.org.br/ foruminternacional2014/>.

\section{O PODER LEVE DA OCDE}

A OCDE declara-se como uma entidade internacional composta por 34 países-membros, majoritariamente desenvolvidos, ${ }^{3}$ que compartilhariam os princípios da democracia representativa e da economia de livre mercado. Sua missão

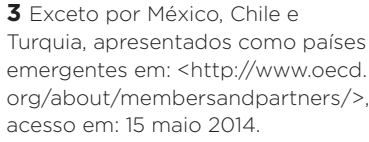


4 De acordo com as informações apresentadas em: <http://www.oecd org/about/>, acesso em: 15 maio 2014
5 Ainda que a OCDE não exerça essa posição abertamente coercitiva. Carvalho (2009 apud RINNE et al., atuação se dá através da "construção de consensos" e da "pressão pelos pares", uma vez que os próprios países-membros se encarregam de realizar entre si esse papel de seria desenvolver, através de políticas, o bem-estar econômico e social das pessoas ao redor do mundo. ${ }^{4}$

Sellar e Lingard (2013) ressaltam que, no que tange à educação, o papel da OCDE mudou significativamente com o tempo, na medida em que o campo educacional ocupava um lugar acessório quando da criação daquela Organização, tendo passado a assumir relevância formalizada institucionalmente com a criação de sucessivas diretorias: Diretoria de Assuntos Sociais, Pessoal e Educação (em 1975); Diretoria para Educação, Emprego, Trabalho e Assuntos Sociais (em 1991); Diretoria de Educação (constituindo-se como campo autônomo em 2002).

Conforme apontam Baker e Le Tendre (2005), a razão para essa crescente importância reside no fato de ser a educação encarada como um setor estratégico para o sucesso de uma nação, especialmente no contexto do capitalismo atual, em que as economias estão permanentemente em disputa pelo poder político e econômico.

A posição de destaque da OCDE justifica-se, em parte, pelo fato de essa instituição internacional orientar suas ações a partir do que se constitui como um "poder leve" ("soft power"). A esse respeito, Eccleston (2011) aponta que a OCDE se distingue das outras instituições criadas após o Acordo de Bretton Woods, no contexto de reconstrução que se estabeleceu com o fim da Segunda Guerra Mundial - tais como o Fundo Monetário Internacional (FMI), a Organização Mundial do Comércio (OMC) e o Banco Mundial -, por não assumir uma posição claramente coercitiva de poder. ${ }^{5}$

A constituição desse "poder leve" estaria relacionada ao fato de a OCDE se apresentar como detentora do conhecimento técnico e promotora de uma rede transgovernamental através da qual os especialistas em políticas públicas poderiam interagir e buscar soluções coordenadas ante a situações difíceis. Esse lugar a partir do qual aquela organização se manifesta mostra-se, sem dúvida, como um locus de suposto auxílio, ao qual os países poderiam recorrer para questões de diversas naturezas, incluídas as educacionais.

Jakobi e Martens (2010) alegam que o "poder leve" exercido pela OCDE, baseado na argumentação persuasiva, seria 
marcado por três mecanismos de governança: a produção de ideias, a avaliação de políticas e a geração de dados. Além desses mecanismos de governança, Woodward (2009) aponta que a OCDE persegue quatro modos de governança: o cognitivo - desenvolvido através de uma agenda cooperativa e da circulação de ideias -, o normativo - observável a partir do compartilhamento de um conjunto de valores -, o legal - associado ao que nomeamos acima como uma legislação branda -, e o paliativo - relacionado ao papel da OCDE entre os demais organismos internacionais.

\section{ANÁLISE DO CORPUS}

Trazemos a seguir dois fragmentos do relatório "Education at a Glance 2013", publicado anualmente pela OCDE, com o objetivo de subsidiar, por meio de indicadores, as políticas públicas não só de seus países-membros, como também dos demais países que participam das avaliações internacionais geridas pela OCDE (2013a, p. 3).

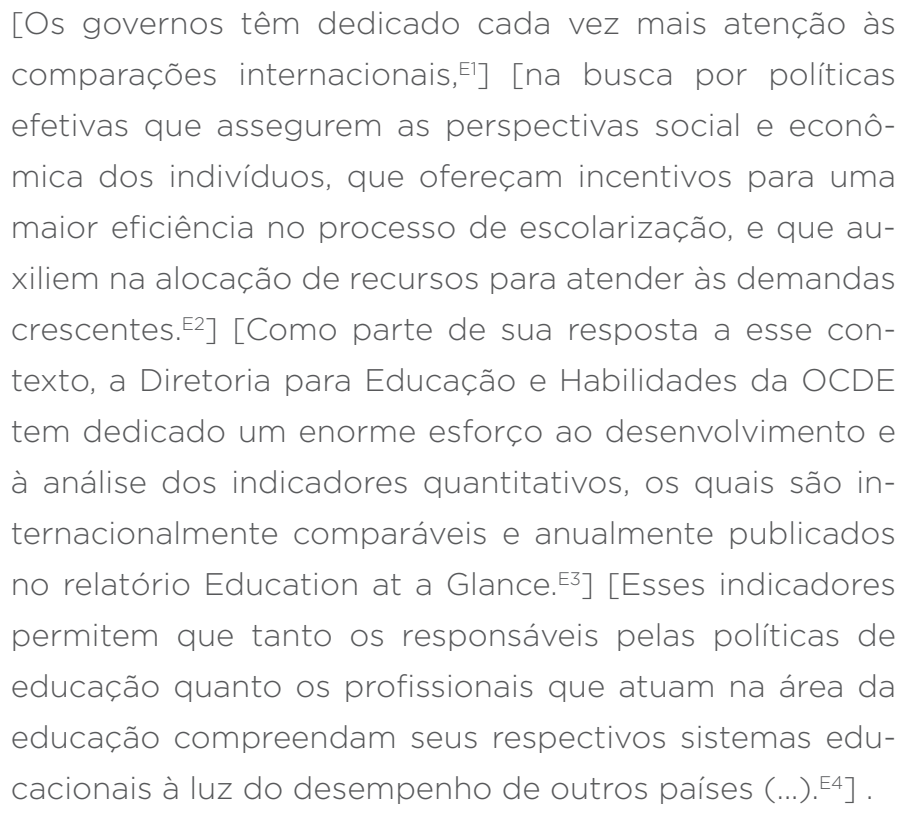

Conforme se vê no fragmento anterior, a OCDE se apresenta (E3) como uma organização que apenas responde aos anseios dos governos (E1), minimizando o seu papel na determinação 
dos rumos educacionais globais. Esse modo de se apresentar reforça a perspectiva de que essa instituição possa exercer um "poder leve", constituindo os três mecanismos de governança apontados por Jakobi e Martens (2010): a produção de ideias (E2), a avaliação de políticas (E4) e a geração de dados (E3).

Já nesse parágrafo introdutório, é possível notar certo desejo por parte desse locutor coletivo de, por um lado, escamotear seu papel na definição do que se deve conceber como um ideal para os indivíduos, para as sociedades e acerca do processo de escolarização (E2), e, por outro, reforçar a concepção de que os indicadores são suficientemente comparáveis (E3), a despeito das enormes diferenças históricas e socioeconômicas observadas entre os países que participam das avaliações internacionais.

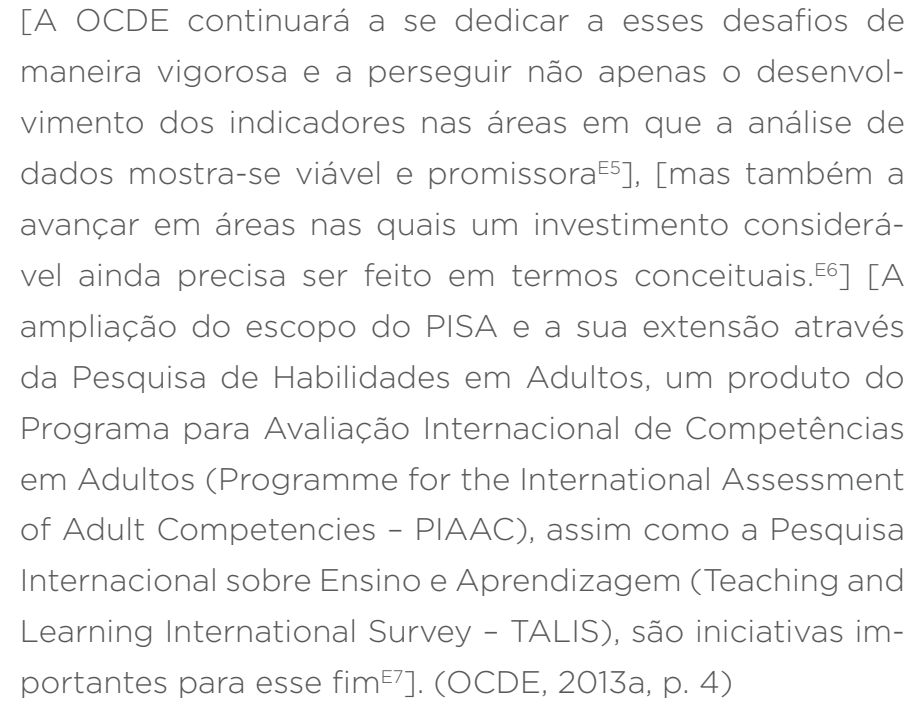

No parágrafo acima, a OCDE compromete-se a expandir sua atuação tanto no que diz respeito ao que acredita estar aferindo há cerca de 15 anos (E5) quanto a novas áreas (E6), tais como a inclusão da habilidade de solucionar problemas de maneira colaborativa - a ser aplicada ao PISA de 2015 -, a iniciativa de avaliar habilidades cognitivas e talvez socioemocionais em adultos - PIAAC - e o programa para avaliação do trabalho docente - TALIS -, em franca expansão (E7).

Ao afirmar que pretendia estender sua atuação para outras áreas, é possível supor que a OCDE já vislumbrasse envolver-se 
com a proposta de desenvolvimento das habilidades socioemocionais. Uma indicação interessante a esse respeito reside na proposta de ampliar a avaliação da habilidade de solucionar problemas - já presente no PISA de 2012 -, abarcando a colaboração no PISA de 2015.

A seguir, apresentamos dois parágrafos extraídos do documento "PISA 2015: draft collaborative problem solving framework", em que a OCDE (2013b, p. 4) apresenta os fundamentos para a avaliação da habilidade de solucionar problemas de modo colaborativo, que será aplicada com o PISA de 2015.

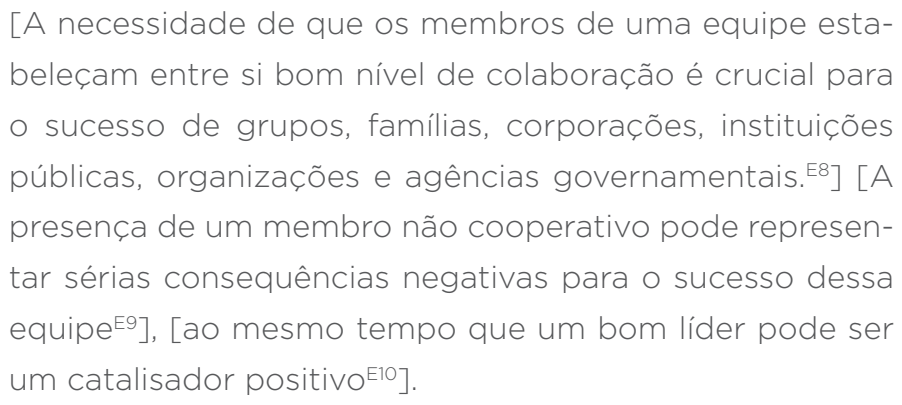

Como se vê, a colaboração é apresentada como um atributo essencial para as coletividades, mencionadas em suas variadas constituições (E8). A referência à possibilidade de que haja um membro não cooperativo em uma equipe é retratada como um risco (E9), ao passo que a liderança ou, antes, a presença de um "bom” líder é tratada como algo desejável.

Poderíamos, a um só tempo, questionar o que a OCDE entende por liderança; e se o desenvolvimento da colaboração nesse contexto específico a que a OCDE se refere - o qual inclui corporações, organizações e agências governamentais - não poderia significar o incentivo a um comportamento de aceitação irrestrita, de não questionamento. É notável, a despeito de fazer questão de destacar que atua apenas em resposta às demandas dos governos, a interferência que essa organização pode vir a ter nos espaços escolares, conforme se vê a seguir:

[A avaliação da habilidade de solucionar problemas de modo colaborativo, a ser aferida como uma das competências do PISA 2015, (...) deve refletir a colaboraçãoE11] [a ser 
Angel Gurría é o Secretário-Geral da OCDE desde 2006, tendo sido, de

1994 a 1998, Ministro das Relações Exteriores do México, e, de 1998 a 2000, Ministro da Economia daquele desenvolvida pelas escolas a partir da aprendizagem baseada em projetos, ${ }^{E 12}$ ] [com vistas à colaboração nos espaços laborativos e nas relações cívicas ${ }^{E 13}$ ] (...) [Nessas configurações, espera-se que os alunos sejam proficientes em se comunicar, em gerenciar conflitos, em organizar equipes, em construir consenso e em monitorar o progresso $\left.{ }^{E 14}\right]$. (OCDE, 2013b, p. 4)

Está bastante clara a expectativa por parte da OCDE acerca do tipo de abordagem pedagógica que as escolas devem adotar (E12) e o que se espera obter a partir dessa abordagem (E13 e E14). Ressaltamos, no entanto, que, embora faça sempre questão de expor suas visões como se estivesse em busca do bem-estar dos indivíduos e de suas famílias, algumas das expectativas explicitadas pela OCDE limitam-se ao mundo do trabalho, como monitorar progresso (E14), por exemplo.

Retornamos ao relatório "Education at a Glance 2013", para abordar três fragmentos da mensagem do Secretário-Geral da OCDE, ${ }^{6}$ apresentada na forma de um editorial.

[Essa edição do Education at a Glance vem a público em um momento em que o desemprego dos jovens tem tirado o sono dos responsáveis pelas políticas públicas ${ }^{E 15}$ ]. [Entre 2008 e 2011 - os anos a que se referem a maior parte dos dados desse volume - as taxas de desemprego se elevaram acentuadamente na maioria dos países, tendo permanecido altas desde entãoE16]. [Os jovens têm sido particularmente afetados pelo desemprego e pelo subemprego como decorrência da recessão global $\left.{ }^{17}\right]$. (OCDE, 2013a, p. 13)

O editorial referido é a única parte do relatório em que nos deparamos com um sujeito-argumentante individual, ainda que este represente a visão oficial da OCDE. O contexto socioeconômico que se vivia entre 2008 e 2011 (E16) - e mesmo nos anos seguintes -, marcado pelas altas taxas de desemprego, que afetou especialmente os jovens, é referido pelo Secretário-Geral como decorrente da recessão global (E17), na forma de uma constatação. Ainda que tenha dado destaque ao fato de o quadro de desemprego entre os jovens tirar o 
sono dos responsáveis pelas políticas públicas (E15), o locutor em si limita-se a observar esse fato, sem propor qualquer discussão sobre suas causas, por exemplo.

Diante do cenário de desemprego entre jovens, ocasionado pela recessão global, a OCDE (2013a, p. 14), por intermédio de seu Secretário-Geral, recomenda mais uma intervenção no âmbito educacional, conforme se vê a seguir:

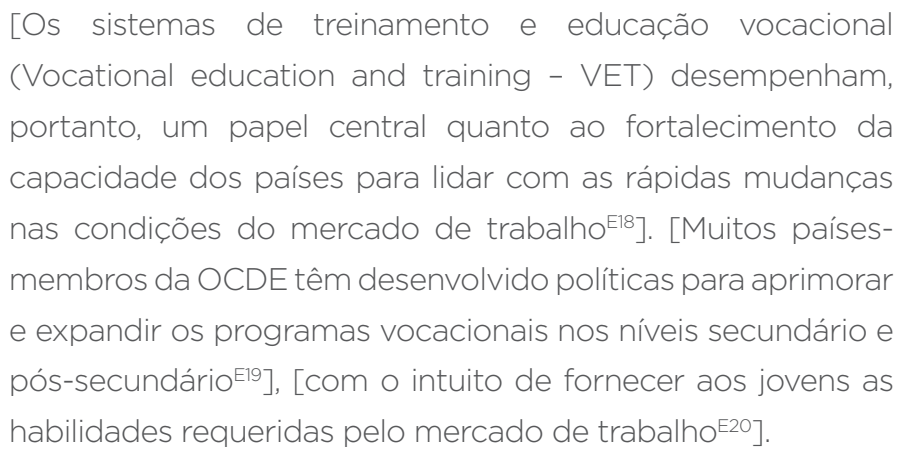

O que está sendo proposto é a adoção de programas vocacionais nas escolas como forma de lidar com as rápidas e constantes mudanças por que estaria passando o mercado de trabalho (E18). Essa proposta é reforçada pelo argumento de que muitos países têm acenado nessa direção (E19) como forma de garantir aos jovens as habilidades necessárias ao mercado de trabalho (E20).

Conforme vimos, não são poucos os autores que têm criticado o paradigma de mercado aplicado à educação e à escola, e muito se tem discutido acerca do papel da escola em relação ao mundo do trabalho. Paro (1999), por exemplo, defende que à escola cabe a preparação para o "viver bem" e para o efetivo exercício da cidadania, e que a ela não caberia a criação dos empregos que o sistema produtivo não teria conseguido criar.

O terceiro fragmento extraído do editorial em questão talvez seja o mais claro e contundente quanto às expectativas da OCDE a respeito do que caberia à educação e de como esta deve ser (re)concebida para que se garanta a empregabilidade dos jovens.

[As altas taxas de desemprego entre os jovens não são inevitáveis, mesmo durante uma crise econômica ${ }^{\mathrm{E2}}$ ]; [elas 
são o resultado da interação entre o contexto econômico e políticas públicas particulares ${ }^{E 22}$. [E, conforme comprovam os dados coletados nos primeiros anos dessa crise, a quantidade de recursos públicos investidos na educação tem pouco a ver com o sucesso ou o fracasso de um país para conter o desemprego entre os jovens ${ }^{\mathrm{E23}}$ ]: [praticamente todos os governos mantiveram mais ou menos o mesmo nível de investimento durante a crise $\left.{ }^{\mathrm{E24}}\right]$. [O que importa mais são as escolhas que os países fazem em como alocar esses recursos e que políticas públicas eles desenvolveram para aprimorar a eficiência e a relevância da educação que oferecem ${ }^{E 25}$ ]. [Os dados e as políticas públicas adotadas nos países revelam que ações são efetivas para estimular a empregabilidade dos jovens ${ }^{\mathrm{E} 26}$ ]: [garantir que todos os jovens atinjam bons niveis tanto de habilidades fundantes (habilidades cognitivas) ${ }^{\text {E27}}$ ] [quanto de habilidades leves (habilidades socioemocionais), tais como a capacidade de trabalhar em equipe, as capacidades de comunicação e de negociaçãoE28], [as quais Ihes garantirão a resiliência necessária para obterem sucesso em um mercado de trabalho em permanente mudança ${ }^{\mathrm{E} 29}$ ]; [reduzir as taxas de evasão escolar e assegurar que o maior número possível de jovens completem a educação secundária (se necessário através de uma segunda oportunidade) ${ }^{E 30}$ ]; [tornar a educação secundária relevante para o desenvolvimento das habilidades necessárias ao mercado de trabalho ${ }^{E 31}$ ]; [desenvolver treinamento e educação vocacionalE32], [e aproximar a educação do mundo do trabalho através da inclusão de aprendizagem baseada no trabalho ("work-based learning") E33]; [assegurar caminhos flexíveis para a educação terciáriaE34]; [e oferecer bons estudos e serviços de orientação para carreiras, de maneira que os jovens possam tomar decisões sensatas e informadas ${ }^{E 35}$ ]. (OCDE, 2013a, p. 15)

Ao afirmar que as altas taxas de desemprego entre os jovens podem ser evitadas, ainda que em contexto de crise envolvendo uma ou várias economias capitalistas (E21), o locutor coloca-se na posição de quem detém determinado 
saber, ignorado pelo interlocutor, revestindo-se, assim, de uma posição de autoridade. Como se vê, o sujeito-argumentante declara que é possível conter as taxas de desemprego em tempos de crise, desde que sejam adotadas as políticas públicas adequadas. Uma declaração como essa certamente reforça a posição da OCDE como um locus de suposto auxílio.

Para comprovar essa declaração, o locutor vale-se de dados contidos no relatório, os quais demonstrariam que os investimentos em educação nos países-membros da OCDE não teriam diminuído no intervalo de crise em questão (E23 e E24); teriam apenas sido alocados de maneira diferenciada à luz de determinadas políticas públicas que teriam sido capazes de "aprimorar a eficiência e a relevância da educação que oferecem" (E25).

Dias Sobrinho (2004), ao defender a necessária superação das noções estreitas de qualidade advindas do mercado à educação, aponta que, quando os níveis de qualidade pretendem ser verificados de acordo com a lógica de mercado, costumam ser empregados três critérios: a pertinência (que podemos entender como sinônimo de relevância) - a qual se inscreve na interseção entre o que se pretende e o que seria necessário do ponto de vista científico e social -, a eficácia aferida na comparação entre as práticas e os objetivos -, e a eficiência - mensurada a partir da relação entre insumos e resultados.

Ao apontar como ideal educacional o aprimoramento da eficiência e da relevância da educação (E25), o Secretário-Geral da OCDE revela uma concepção de ensino e de educação marcada pela operatividade e pela funcionalidade produtiva, o que se comprova pela extensa lista de ações (E26) que seriam capazes de garantir a empregabilidade dos jovens (E27 a E35).

Nesse sentido, torna-se muito clara a posição da OCDE quanto à importância não só das habilidades cognitivas (E27), mas também das habilidades socioemocionais (E28), dentre as quais são explicitamente mencionadas a colaboração, a comunicação e a negociação, altamente vinculadas às expectativas do mercado de trabalho (E29). 
7 compareceram ao evento altos representantes da área de educação dos seguintes países: Argentina, Brasil, Colômbia, Coreia do Sul, Equador, Estados Unidos, Letônia México, Noruega, Paraguai, Peru Portugal, Suécia e Uruguai.
Ao apresentar explicitamente algumas habilidades socioemocionais como importantes para garantir a empregabilidade dos jovens, a OCDE revela que o campo das habilidades socioemocionais seria uma daquelas novas áreas em direção às quais expandiria sua atuação (E6).

Esse interesse pelas habilidades socioemocionais como uma dessas novas áreas de atuação pôde ser comprovado por ocasião do Fórum Internacional de Políticas Públicas "Educar para as Competências do Século 21", organizado, em parceria, pelo MEC, pela OCDE e pelo IAS.

Transcrevemos a seguir alguns trechos de dois dos documentos produzidos em função do referido evento: o relatório "Competências para o Progresso Social", confeccionado antes do evento e utilizado como documento orientador para os debates realizados (de E36 a E44); e o Sumário realizado a partir do Fórum de Ministros, o qual teria reunido, no dia 24 de março, 14 ministros e altos representantes de países-membros da OCDE e de outras nações ${ }^{7}$ (de E45 a E52).

[O atual contexto socioeconômico traz novos desafios que afetam o futuro de crianças e jovens. ${ }^{E 36}$ ] [Embora o acesso à educação tenha melhorado consideravelmente ${ }^{\text {E37}}$ ], [uma boa educação não é mais suficiente para garantir um bom emprego. ${ }^{E 38}$ ] [Os jovens foram particularmente afetados pelo aumento do desemprego após a crise financeira. $\left.{ }^{E 39}\right]$ $[\ldots]$

[A maioria dos países membros e parceiros da OCDE reconhece a necessidade de desenvolver as competências socioemocionais dos alunos ${ }^{\mathrm{E} 0}$ ], [como autonomia, responsabilidade e habilidade para cooperar com os outros ${ }^{\text {E41 }}$. [As evidências fornecidas no relatório de apoio deste Fórum identificam uma variedade de iniciativas promissoras para o desenvolvimento dessas competências ${ }^{E 42}$. [No entanto, o relatório também informa que há lacunas nos níveis de conhecimento e de esforços relacionados às melhores formas de estimular as competências socioemocionais das crianças. ${ }^{E 43}$ ] [Os diversos atores envolvidos na área de educação devem compartilhar conhecimento sobre as melhores políticas e práticas que promovam essas competências. ${ }^{\mathrm{E44}}$ ] (OCDE, 2013a, p. 1,5) 
Como se vê, o relatório "Competências para o Progresso Social" apresenta forte alinhamento - tanto de ideias como de valores - com o relatório "Education at a Glance 2013". Esse alinhamento é percebido, por exemplo, quando pensamos os seguintes pares de enunciados: E39 e E17; E40 e E28; E44 e E26.

No entanto, é possível perceber algumas diferenças importantes, embora por vezes sutis, entre o que se apresenta em cada um dos documentos. No relatório "Competências para o Progresso Social", observa-se a perspectiva de que uma "boa" educação não seria garantia de um "bom" emprego (E38), ao passo que no relatório "Education at a Glance 2013", a empregabilidade apresenta-se condicionada à eficiência e à relevância da educação (E25). Para além da dificuldade de se definir o que seria uma "boa" educação e um "bom" emprego - o que exigiria uma visão de mundo com alto nível de compartilhamento -, é possível notar no relatório vinculado ao evento uma associação mais explícita entre a hipótese - tratada como tese - de que o desenvolvimento das habilidades socioemocionais levaria à garantia de um "bom" emprego, enquanto no relatório anual de indicadores da OCDE muitos outros fatores foram considerados como forma de garantir a empregabilidade (de E27 a E35).

A comparação entre os dois relatórios permite-nos notar também diferenças não só na forma de designar as habilidades socioemocionais - "habilidades leves" (de soft skills) em "Education at a Glance 2013" e "competências socioemocionais" em "Competências para o Progresso Social" - como também na exemplificação que se escolheu dar dessas habilidades colaboração, comunicação, negociação e resiliência, no primeiro caso (E28 e E29); e autonomia, responsabilidade e cooperação, no segundo (E41).

A expressão "habilidades leves" tem sido empregada nos campos da neurociência e da economia, na perspectiva da formação do capital social. Já os termos "competências socioemocionais" ou "habilidades socioemocionais" têm figurado com maior frequência em contextos mais voltados para a educação. Essa variação terminológica permite-nos entrever um esforço por parte da OCDE de se adequar a uma 
terminologia mais facilmente aceita pela área da educação. A esse respeito, não se pode ignorar o fato de que o evento em questão foi concebido para atingir os sistemas educacionais dos países envolvidos, através de seus ministros da educação ou altos representantes da cena educacional.

Esse mesmo movimento em direção ao contexto educacional é observado quando consideramos a exemplificação das habilidades socioemocionais contida em cada um dos relatórios. De fato, negociação é uma habilidade muito voltada para as demandas do mercado do trabalho, ao passo que as habilidades exemplificadas no relatório "Competências para o Progresso Social” poderiam figurar, sem causar qualquer estranhamento, no ambiente escolar.

Ainda que o relatório em questão reporte a existência de iniciativas promissoras para o desenvolvimento das habilidades socioemocionais (E42), o documento reconhece a existência de "lacunas" quanto às "melhores" maneiras de desenvolvê-las (E43). A solução para isso estaria no compartilhamento de conhecimento entre os atores envolvidos na área da educação (E44).

Essa estratégia de ressaltar a potencialidade do compartilhamento não só de conhecimento como também de "boas" práticas tem sido adotada pela OCDE para justificar sua atuação no campo educacional. Kamens (2013) aponta, no entanto, que a concepção de que as boas práticas seriam replicáveis em outros contextos é um grave engodo que a OCDE parece fazer questão de reforçar.

As tais lacunas reconhecidas pela OCDE teriam motivado a organização a trazer outras vozes para discutir as habilidades socioemocionais, conforme se observa nos fragmentos a seguir, extraídos da conclusão do Sumário realizado a partir do Fórum de Ministros.

[Formuladores de políticas públicas de todo o mundo, incluindo cinco ministros e seis vice-ministros de Educação, reconhecem a importância das competências cognitivas e socioemocionais para bons resultados na vida dos indivíduos. ${ }^{E 45}$ [ [Participantes destacaram a importância de habilidades de letramento e numeramento, assim como trabalho em equipe, perseverança, resiliência e comunicação. E46] 
$[\ldots]$

[A OCDE continuará a fazer esforços para ajudar a fortalecer a base de dados em um estudo longitudinal sobre a formação de competências desde a infância até a adolescência em diferentes países. ${ }^{E 47}$ ] [Nós também vamos continuar buscando contribuições de grandes cientistas, como o professor Heckman, ${ }^{E 48}$ ] [para que os países compartilhem o conhecimento para melhorar as decisões de políticas públicas. ${ }^{\mathrm{49}}$ ] [Por último, mas não menos importante, nós vamos continuar a trabalhar junto aos países da OCDE e parceiros ${ }^{E 50}$ ] [para aprender com suas experiências e para promover as competências socioemocionais entre os diferentes atores. ${ }^{[51}$ ] [Estamos certos de que esses esforços serão complementares aos investimentos consideráveis que já são feitos (ou planejados) pelo Ministério da Educação do Brasil e pelo Instituto Ayrton Senna. ${ }^{552}$ ] (OCDE, 2013a, p. 4)

Essas outras vozes explicitamente mencionadas no documento fariam referência aos ministros, vice-ministros e demais autoridades educacionais (E45); aos cientistas e, em especial, ao Professor de Economia James Heckman (E48); ao MEC e ao IAS (E52).

É interessante notar a estratégia argumentativa da universalização empregada ao se defender que a importância das competências cognitivas e socioemocionais para a vida dos indivíduos seria reconhecida por formuladores de políticas públicas de todo o mundo (E45). Ao fazê-lo, a OCDE estaria perseguindo não só o que Woodward (2009) concebeu como modo de governança cognitivo - o qual passa pela circulação de ideias -, mas também o modo de governança normativo - observável a partir do compartilhamento de um conjunto de valores.

Consideramos de extrema importância destacar que, apesar de o evento em questão ter sido realizado, em parceria, pela OCDE, pelo MEC e pelo IAS, o Sumário do Fórum de Ministros fora confeccionado exclusivamente pela OCDE. ${ }^{8}$ Seria essa uma das estratégias da OCDE para assegurar pontos de convergência entre os aspectos priorizados em

8 Na primeira página do documento, disponível no site do IAS, encontrase a seguinte frase: "Este sumário foi produzido pela equipe do projeto Education and Social Progress, da OCDE, e publicado sob sua responsabilidade". 
suas recomendações e relatórios e as futuras políticas instituídas pelos governos locais, conforme sugerem Shiroma, Garcia e Campos (2011).

\section{CONCLUSÃO}

A garantia de que manterá seus esforços para coletar dados acerca das habilidades socioemocionais em diferentes países, a busca pelo respaldo de cientistas para que os países compartilhem o conhecimento a respeito dessas habilidades e a expectativa explicitamente declarada de que o MEC e o IAS façam investimentos nessa área sugerem a existência de um projeto mais amplo por parte da OCDE, do qual o Brasil poderia cumprir um papel relativamente limitado.

Em relação ao desenvolvimento das habilidades socioemocionais, ressaltamos que a OCDE tem feito bem mais do que simplesmente responder aos anseios dos governos. A análise de nosso corpus permite-nos afirmar que essa organização tem posto em prática um verdadeiro projeto de governança educacional global, constituindo, por um lado, os três mecanismos de governança apontados por Jakobi e Martens (2010), quais sejam a produção de ideias, a avaliação de políticas e a geração de dados e, por outro, os modos de governança cognitivo e normativo, concebidos por Woodward (2009).

O projeto de governança educacional global exercido pela OCDE tem legitimado o envolvimento e a atual precedência dos economistas na definição dos rumos da educação, em detrimento dos próprios educadores, entrevistos, sobretudo através da mídia, como ideólogos sem propostas concretas.

Podemos mesmo dizer que esse projeto - marcado, por um lado, por um discurso que tende a deslegitimar as vozes dos educadores, e, por outro, por uma ação não percebida como coerci-

9 Embora o Brasil ainda não tenha se tornado um país-membro da OCDE, este revela forte alinhamento à su proposta de avaliação internacional. O país é atualmente considerado pela organização como um parceiro-chave, conforme anunciado em: $<$ http://www.oecd.org/about/ membersandpartners/>, Acesso em: 15 maio 2014 tiva, pois que revestida de uma intenção de compartilhamento de conhecimento técnico e de prestação de auxílio - vem encontrando no Brasil um terreno altamente fértil.9

Considerando que todo esse processo de valorização das habilidades socioemocionais venha sendo protagonizado 
pela OCDE e que, como comprovado em nosso corpus, a visão desse organismo multilateral acerca da educação esteja fortemente relacionada às demandas estabelecidas pelo mercado de trabalho, o projeto que ora se afigura de incentivar o fomento às habilidades socioemocionais e de aferi-las por meio de avaliação em larga escala se assenta nas expectativas do que o mercado de trabalho vem definindo como perfil desejado para os indivíduos que emprega e no desejo de instituir formas de controle para assegurar que tais expectativas sejam atendidas.

\section{REFERÊNCIAS}

BAKER, D.; LE TENDRE, G. Global similarities and national differences. Stanford, CA: Stanford University, 2005.

BALL, S. Sociologia das políticas educacionais e pesquisa crítico-social: uma revisão pessoal das políticas educacionais e da pesquisa em política educacional. In: BALL, S.; MAINARDES, J. (Org.). Políticas educacionais: questões e dilemas. São Paulo: Cortez, 2011.

CARVALHO, L. Governando a educação pelo espelho do perito: uma análise do Pisa como instrumento de regulação. Educação e Sociedade, Campinas, SP, v. 30, n. 109, p. 1009-1036, set./dez. 2009.

CHARAUDEAU, P. Linguagem e discurso: modos de organização. São Paulo: Contexto, 2014.

DIAS SOBRINHO, J. A avaliação ética e política em função da educação como direito público ou como mercadoria?. Educação e Sociedade, Campinas, SP, v. 25, n. 88 , p. 703-725, out. 2004.

ECCLESTON, R. The OECD and Global Economic Governance. Australian Journal of International Affairs, London, v. 65, n. 2, p. 243-255, Apr. 2011.

FARKAS, G. Cognitive skills and noncognitive traits and behaviors in stratification processes. Annual Review of Sociology, Palo Alto, CA, v. 29, p. 541-562, Aug. 2003.

GERWITZ, S.; BALL, S. Do modelo de gestão do 'Bem-Estar Social' ao 'novo gerencialismo': mudanças discursivas sobre gestão escolar no mercado educacional. In: BALL, S.; MAINARDES, J. (Org.). Políticas educacionais: questões e dilemas. São Paulo: Cortez, 2011.

GRUBB, W. N.; LAZERSON, M. The globalization of rhetoric and practice: the education gospel and vocationalism. In: LAUDER, H.; BROWN, P.; DILLABOUGH, J. A.; HALSEY, A. H. (Org.). Education, globalization and social change. Oxford: Oxford University, 2006. p. 295-307. 
HECKMAN, J. J.; STIXRUD, J.; URZUA, S. The effects of cognitive and noncognitive abilities on labor market outcomes and social behavior. Journal of Labor Economics, Chicago, v. 24, n. 3, p. 411-482, July 2006.

JAKOBI, A.; MARTENS, K. Introduction: the OECD as an actor in international politics. In: MARTENS; K.; JAKOBI, A. (Ed.). Mechanisms of OECD Governance: international incentives for national policy-making?. Oxford: Oxford University, 2010.

KAMENS, D. Globalization and the emergence of an audit culture: Pisa and the search for 'best practices' and magic bullets. In: MEYER, H-D.; BENAVOT, A. (Org.). Pisa, power and policy: the emergence of global education governance. Oxford: Symposium Books, 2013.

LEVIN, H. More than just test scores. Prospects: Quarterly Review of Comparative Education, Palo Alto, CA, v. 42, n. 3, p. 269-284, Sept. 2012.

MEYER, H-D.; BENAVOT, A. Pisa and the globalization of education governance: some puzzles and problems. In: MEYER, H-D.; BENAVOT, A. (Org.). Pisa, power and policy: the emergence of global education governance. Oxford: Symposium Books, 2013.

ORGANIZAÇÃO PARA A COOPERAÇÃO E DESENVOLVIMENTO ECONÔMICO. Education at a Glance 2013: OECD indicators. Paris: OECD, 2013a.

ORGANIZAÇ̃̃O PARA A COOPERAÇ̃̃O E DESENVOLVIMENTO ECONÔMICO. Pisa 2015: draft collaborative problem solving framework. Paris: OECD, 2013b.

PARO, V. Parem de preparar para o trabalho! Reflexões acerca dos efeitos do neoliberalismo sobre a gestão e o papel da escola básica. In: FERRETTI, C. et al. (Org.). Trabalho, formação e currículo: para onde vai a escola?. São Paulo: Xamã, 1999.

RAVITCH, D. National opportunity to learn summit. 2011. Disponível em: $<$ http://www.ucc.org/justice/public-education/pdfs/NatlOTL.pdf $>$. Acesso em: 15 nov. 2014

SELLAR, S.; LINGARD, B. Pisa and the expanding role of the OECD in global educational governance. In: MEYER, H-D.; BENAVOT, A. (Org.). Pisa, power and policy: the emergence of global education governance. Oxford: Symposium Books, 2013.

SHIROMA, E.; GARCIA, R.; CAMPOS, R. Conversão das 'almas' pela liturgia da palavra: uma análise do discurso do movimento Todos pela Educação. In: BALL, S.; MAINARDES, J. (Org.). Políticas educacionais: questões e dilemas. São Paulo: Cortez, 2011.

WOODWARD, R. The Organization for Economic Cooperation and Development (OECD). Abingdon, MA: Routledge, 2009. 


\section{CARLOS EDUARDO SERRINA DE LIMA RODRIGUES}

Doutorando em Educação no Programa de Pós-Graduação

em Educação da Universidade Federal do Estado do

Rio de Janeiro (PPGEDU/Unirio), Rio de Janeiro,

Rio de Janeiro, Brasil

rodrigues.ces!@gmail.com

\section{CLAUDIA DE OLIVEIRA FERNANDES}

Professora do Programa de Pós-Graduação em Educação da Universidade Federal do Estado do Rio de Janeiro

(PPGEDU/Unirio), Rio de Janeiro, Rio de Janeiro, Brasil

clof52.cf@gmail.com 